\title{
O IMPACTO DAS STARTUPS DO AGRONEGÓCIO (AGROTECHS) NO MERCADO BRASILEIRO
}

THE IMPACT OF AGRITECHS ON THE BRAZILIAN MARKET

\author{
Ricardo Reolon Jorge \\ UFABC/CECS/Engenharia de Gestão \\ reolon.ricardo@ufabc.edu.br \\ Júlio Francisco Blumetti Facó \\ UFABC/CECS/Engenharia de Gestão \\ julio.faco@ufabc.edu.br \\ (D) orcid https://orcid.org/0000-0002-8155-5547
}

\author{
Alexandre Acácio de Andrade \\ UFABC/CECS/Engenharia de Gestão \\ aacacio@ufabc.edu.br
}

orcid https://orcid.org/0000-0002-9794-8687

\section{RESUMO}

Este trabalho apresenta um mapeamento do cenário do agronegócio brasileiro, bem como as startups que nele se desenvolveram, conhecidas como agrotechs. É nesse contexto que são apresentados dados para mensurar o tamanho e potencial do mercado do agronegócio. Com isso, verificou-se a necessidade de detalhar as principais características das agrotechs. Para tal, houve a análise minuciosa de três startups desse segmento. Este detalhamento foi obtido através da realização de um questionário aberto, com o objetivo de facilitar a compreensão das respostas encontradas sem restringi-las. Os principais temas abordados com as agrotechs entrevistadas foram quanto às tecnologias por elas utilizadas, bem como os principais motivadores e desafios encontrados no início do negócio. 0 presente trabalho tem então o objetivo de esclarecer o panorama brasileiro em que as agrotechs estão inseridas.

Palavras-chave: Startup, agronegócio, agritech, negócio. 


\section{ABSTRACT}

The present paper intents to detail the Brazilian agribusiness scenario, and also the startups that were developed, known as agritechs. In this context, data are brought to measure the size and the potential of the agribusiness market. It was necessary then to detail the characteristics of the agritechs. This detailing process was obtained through the creation of a questionnaire, with the purpose of making easier the comprehension of the answers without restraining then. The questions were based on the technologies the agritechs use, as well as the motivations and challenges that happened in the beginning. The paper has the purpose of clarifying the Brazilian agritechs and the impact of then in Brazilian market.

Keywords: Startups, agribusiness, agritech, business

JEL Classification: M13 New Firms • Startups. 


\section{INTRODUÇÃO}

Embora o empreendedorismo seja considerado por muitos como campo de pesquisa relativamente novo, Verga e Silva (2014) afirmam que a função de empreender é tão antiga quanto o comércio de produtos e serviços entre indivíduos de um grupo, conforme citado anteriormente por Landström, Harirchi, Aström (2012). No entanto, apesar do conceito ser praticado há tempo considerável, apenas com a evolução dos mercados, o tema passou a ser discutido.

Murphy, Liao e Welsch (2006) afirmam que a atividade empreendedora passou a ganhar notoriedade a partir dos séculos XVI e XVII, quando o conhecimento começou a ser atrelado às habilidades do indivíduo e tinha como objetivo buscar soluções e corrigir ineficiências. Assim, o empreendedorismo passou a desenvolver-se atrelado aos pensamentos que dominavam a época em questão. Com isso, Landström e Benner (2010) dividiram em três eras distintas o pensamento empreendedor. As mesmas estão representadas abaixo e seus principais pontos são discutidos a seguir:

Figura 1: Três Eras do Pensamento Empreendedor

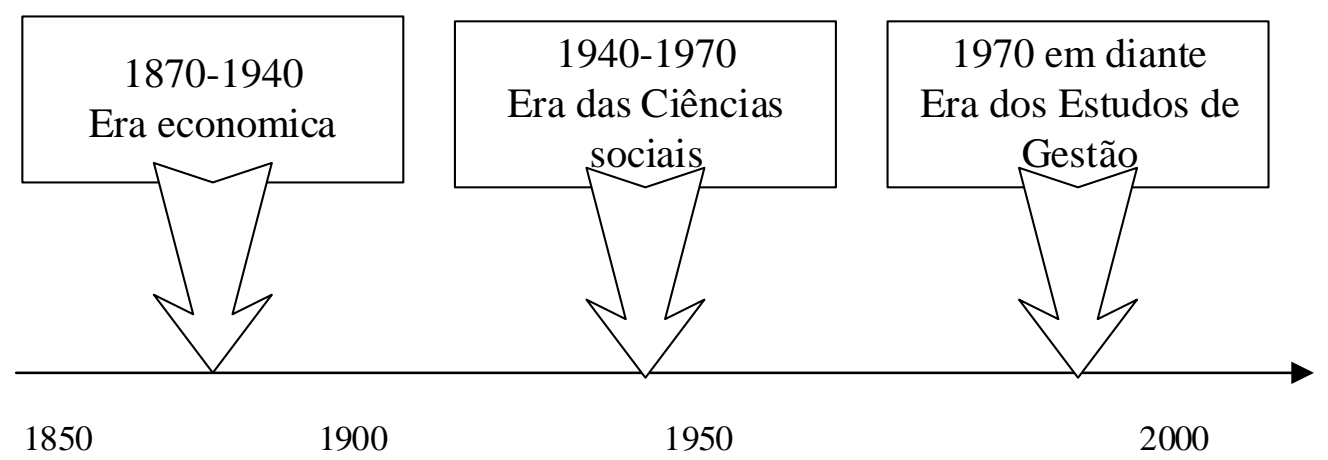

Fonte: Verga e Silva (2014 p. 3)

A primeira era, conhecida como Era Econômica, está compreendida entre 1870 e 1940 e segundo Verga e Silva, os principais pontos apresentados nesta época são a abordagem dos riscos, com foco nas incertezas, destacando ainda para a abordagem Schumpeteriana, que passa a atrelar diretamente ao desenvolvimento econômico as mudanças e inovações tecnológicas. Por sua vez, a Era das Ciências Sociais (1940-1970) foi marcada pelo estudo do empreendedor como um indivíduo em que psicólogos e sociólogos passam a investigar traços de sua personalidade e relacionar o empreendedorismo a um 
comportamento desviante. Por fim, a Era dos Estudos de Gestão (1970-em diante) iniciase quando o empreendedorismo se torna um tema central na sociedade e diferentes escolas de pensamento iniciam suas pesquisas nesse campo. A era em questão é marcada por mudanças políticas, econômicas e tecnológicas, além do acesso à informação, gerando crescimento exponencial de interesse pelo tema.

\section{EMPREENDEDORISMO E INOVAÇÃO}

Baron e Shane (2007) definem em seu livro "Empreendedorismo: uma visão do processo" o conceito de empreender como:

"o empreendedorismo, como uma área de negócios, busca entender as oportunidades para criar algo novo (novos produtos ou serviços, novos mercados, novos processos de produção ou matérias-primas, novas formas de organizar as tecnologias existentes); como são descobertas ou criadas por indivíduos específicos que, a seguir, usam meios diversos para explorar ou desenvolver essas coisas novas, produzindo assim uma nova gama de efeitos" (BARON; SHANE, 2007, p. 06)

Assim, o empreendedorismo está, por definição, ligado intrinsecamente a identificação de oportunidades, criando algo novo ou propondo melhorias em produtos e processos já existentes. Segundo Fiorin et al. (2010), essas mudanças são comumente chamadas de inovação e essa característica está presente em grande parte das definições de empreendedorismo. Fiorin referencia Zawinslak (2007) em seu texto e afirma que inovação pode ser entendida como "uma ação organizacional de aplicação de novos valores cujos resultados são reconhecidos por vantagem econômica".

Considerando então empreendedorismo e inovação como conceitos diretamente ligados, pode-se afirmar que ambos impulsionam o desenvolvimento econômico, teoria defendida por Joseph Alois Schumpeter (1883-1950). Schumpeter (1961) afirma que a inovação tecnológica constante cria rupturas no sistema econômico, tirando-o de um estado de equilíbrio, criando novos processos e padrões, resultando assim em diferenciação entre as empresas. O economista cunhou então o termo "destruição criativa" e dividiu o processo de inovação em três fases, diferenciando conceitos como invenção e inovação por sua aplicabilidade comercial:

- Invenção: geração de novas ideias, com potencial para exploração comercial;

- Inovação: exploração comercial da invenção em questão; 
- Difusão: caso a inovação seja adotada pelo mercado, novos produtos e processos são criados

Camargo et al. (2008) trazem a visão de Schumpeter em relação ao empreendedor, considerado pelo economista como agente essencial do processo de desenvolvimento, que atua por meio da realização de algo que normalmente não é feito na trajetória comum da rotina dos negócios, ou seja, através de processos que têm como característica marcante a inovação. Schumpeter considera ainda a inovação como "a chave para a criação de novas demandas por produtos e serviços" e conceitua o papel do empreendedor como "o agente que inicia novos negócios para explorar essa inovação", e é também o responsável por destruir a ordem econômica presente.

\subsection{Tipos de inovação}

Ao relacionarmos a inovação ao desenvolvimento econômico, teoria defendida por Schumpeter, torna-se necessário entender as características, natureza e fontes do processo de inovação. O economista defende que a inovação se dá através de diferentes elementos: inovação de um processo para a indústria, abertura de um novo mercado, desenvolvimento de novas formas de obtenção de matéria prima ou demais insumos utilizados e ainda mudanças na organização industrial. Assim, Pantaleão et. al (2007) destacam que ainda que a inovação venha a ser em um produto específico, áreas envolvidas na criação e desenvolvimento do mesmo são englobadas por outras formas de inovação. É o caso das áreas de logística, produção, marketing, vendas, desenvolvimento do processo, distribuição e pós-vendas, em que outros tipos de inovação são requeridos.

Segundo Lemos (2000), as inovações podem ser radicais ou incrementais. No primeiro tipo, são consideradas inovações o desenvolvimento de um produto, processo ou forma de organização inteiramente nova, representando assim uma ruptura estrutural no padrão tecnológico existente. As inovações incrementais, por outro lado, referem-se à melhoria de um produto ou organização dentro da empresa, sem alterar, contudo, a estrutura industrial existente. Exemplos de inovações incrementais são otimizações e mudanças nas características estruturais dos produtos.

\section{STARTUPS}


Segundo Michaelis (2017), startup é uma "empresa de pequeno porte, com investimento de baixo custo, que privilegia projetos promissores, geralmente na área de alta tecnologia." É um termo que se popularizou nos anos 90 junto a primeira grande bolha da internet. Nesse período, muitos empreendedores com ideias relacionadas à tecnologia, receberam investimentos para seus projetos e com o tempo se mostraram altamente rentáveis. Grande parte dessas empresas surgiram no Vale do Silício, região da Califórnia, Estados Unidos, que agora é famosa justamente pelo grande número de ideias e empresas de sucesso que ali nasceram e prosperaram. Google, Facebook e Apple são exemplos importantes de empresas que começaram no Vale do Silício.

No Brasil de acordo com a Associação Brasileira de Startups (ABStartups), as primeiras startups surgiram no início do século 21, sendo que a partir de 2010 houve um crescimento exponencial no número de empresas.

Ainda que haja um boom na quantidade de startups criadas, é importante salientar que nem toda nova empresa é uma startup.

Segundo Yuri Gitahy (Moreira, 2016), investidor-anjo e fundador da primeira aceleradora de startups no Brasil: "uma startup é um grupo de pessoas à procura de um modelo de negócios repetível e escalável, trabalhando em condições de extrema incerteza."

Aprofundando-se na definição, Yuri busca explicar os conceitos envolvidos. Assim, um cenário de incerteza nada mais é do que a falta de capacidade de afirmar se aquela ideia irá realmente dar certo. O modelo de negócios da startup é a forma com a qual ela gera valor. A forma de gerar valor através do produto ou serviço ofertado varia de acordo com o tipo de negócio no qual a empresa está inserida.

A necessidade de ser repetível significa a capacidade de reproduzir e entregar o mesmo produto em grande escala, onde o foco não é a adaptação do mesmo para o cliente. Assim, Gitahy dá o exemplo da venda de filmes, onde apesar de não ser possível vender o mesmo DVD mais de uma vez, o modelo de pay-per-view possibilitou a distribuição em massa do mesmo filme, sem que fossem necessárias mudanças na produção do mesmo ou que sua disponibilidade fosse impactada.

Por fim, a chave da startup é a sua possibilidade de ser escalável. Isso significa que ainda que seu crescimento seja relevante, o modelo que negócios que a mesma adotou não deverá ser influenciado e seus recursos, sejam eles humanos ou financeiros, não 
devem crescer na mesma proporção. Ao longo do tempo, as receitas devem aumentar consideravelmente, ao passo que os custos têm aumento gradual e linear de acordo com o tempo, diretamente relacionado à quantidade ofertada do produto ou serviço. Com isso, após um tempo definido, as receitas passam a ser muito mais consideráveis do que o custo de obtenção daquele produto ou serviço. O gráfico abaixo busca exemplificar de forma simples e concisa os custos e receitas que uma startup apresenta.

\section{Gráfico 1: Relação entre os custos e receitas em startups de forma geral.}

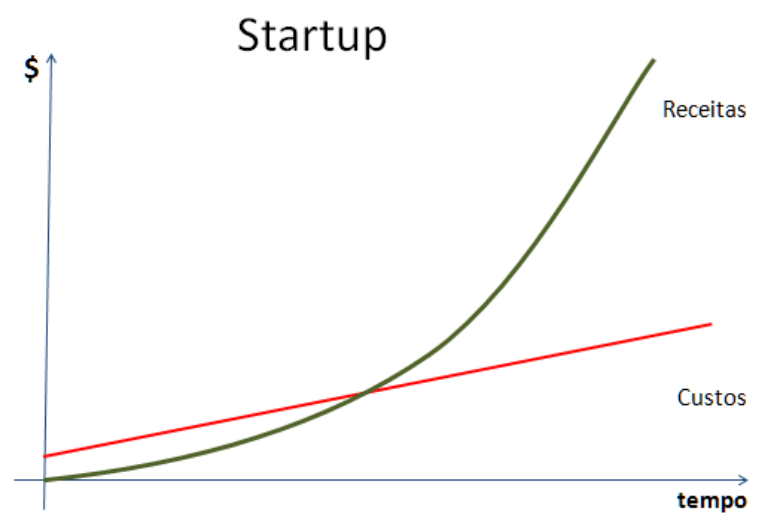

Fonte: [Nei Grando, 2014].

Assim, não é possível definir startup com base em um único conceito, mas é necessário ressaltar que, para ser considerada como uma startup, a empresa deve ter como a inovação, escalabilidade, flexibilidade, formato de negócio enxuto e repetibilidade como suas principais características.

Trazidas as características que definem as novas empresas como startups, é importante destacar que uma startup pode ser classificada ainda de acordo com as características presentes em sua concepção. Assim, a mesma pode ser dividida entre 6 tipos. São eles:

- Lifestyle Startups: são as startups em que o empreendedor busca unir aos negócios suas paixões e hobbies, visando não apenas o lucro, mas sim concretizar suas ideias e tornar real aquilo que acreditam

- Small-Business Startups: nesta categoria, estão inseridos os pequenos empresários, que buscam prosperar o negócio, ainda que seu objetivo principal não seja uma expansão muito ambiciosa. O próprio empreendedor comanda e controla 
a própria empresa e, na maior parte das vezes, trabalha com o objetivo de manterse financeiramente.

- Scalable Startups: Ao contrário dos empresários de pequenos negócios, essas startups já nascem com o objetivo de tornarem-se escaláveis e atingir grandes níveis de difusão. Para isso, precisam cada vez mais de capital, investidores e clientes.

- $\quad$ Buyable Startups: podem ser definidas como empresas que nasceram de boas ideias, mas necessitam de investidores para viabilizar a execução do projeto. O capital investido pode ser conseguido através de investidores anjo ou através de crowdfunding, prática que consiste no financiamento coletivo.

- Social Startups: esse tipo de startup tem como principal objetivo, mas não único, modificar o mundo e tentar transformá-lo em um lugar melhor, através de ideias sociais e que buscam fazer a diferença

- Large-Company Startups: por fim, esse modelo de startup reúne empresas que apesar de já consolidadas, direcionam parte seus recursos para a criação de novos modelos de negócios, com o objetivo de se reinventarem e estarem sempre aptas a lidarem com ameaças externas, concorrentes e a permanecerem no mercado.

Assim, da mesma forma que existem diversas classificações para startups, é possível ainda estabelecer alguns segmentos principais que as startups vêm se consolidando e podem ser consideradas promissoras já que possuem vasto mercado que pode ser explorado por esse modelo de negócio. São alguns exemplos as fintechs, startups especializadas em serviços financeiros; startups nas áreas de educação, com o desafio de aplicar a educação à distância; startups voltadas para a área da saúde, seja interagindo com planos de saúde, seja na recente "onda fitness" e ainda startups voltadas para o agronegócio, conhecidas como Agrotechs.

\section{SEGMENTO ESCOLHIDO: AGROTECHS}

Partiu-se então do princípio que independente do setor ou segmento, startup é aquele modelo de negócio em que temos escalabilidade (capacidade de obter um 
crescimento de forma exponencial). Para atingir esse crescimento é necessário que o mercado/segmento esteja disposto a consumir o produto gerado por essa startup. Estabelecendo essa correlação é possível iniciar o estudo das startups do agronegócio no Brasil.

O agronegócio, bem como os processos nele compreendidos, foi conceituado por John Davis e Ray Goldberg em 1957 como "a soma das operações de produção e distribuição de suprimentos agrícolas, das operações de produção nas unidades agrícolas, do armazenamento, processamento e distribuição dos produtos agrícolas e itens produzidos a partir deles". (Batalha et. al, 1997).

Diante da necessidade de escalabilidade, o setor do agronegócio tem sido um prato cheio para as startups. Representante de $20 \%$ do PIB do país e responsável por $50 \%$ das exportações, o agronegócio hoje pode ser considerado o setor mais importante da economia brasileira. Dado o seu tamanho e a posição estratégica que possui, a probabilidade de obter um crescimento considerável nesse nicho é alta. Em paralelo a esse crescimento, vemos a criação e atuação de inúmeras startups no setor. Essas startups auxiliam o agricultor em todas as etapas do seu ciclo de produção, partindo do plantio até a logística de entrega do produto final.

Com o crescimento citado acima, é natural que haja uma onda de modernização no setor. Essa modernização criou necessidades que até então eram inexistentes e por consequência, desprovidas de solução. Em cima dessa necessidade, startups acabaram surgindo, ainda que nem todas tenham tido o sucesso esperado. Então, além de uma análise dos casos de sucesso e sua importância na economia, é plenamente válido uma breve análise dos motivos pelos quais algumas não obtiveram sucesso mesmo tendo um mercado interessado e necessitado de soluções.

Segundo a ABStartups, nos últimos dois anos o número de startup ligadas ao agronegócio quase duplicou, chegando hoje a cerca de 200 no país. A maioria dessas startups hoje estão incubadas nas universidades e tem como principal foco diminuir custos e otimizar recursos nas mais variadas etapas do ciclo produtivo. Segundo um levantamento feito pela Agritech Startups Brasil, em dezembro de 2016, 53\% das agrotechs têm membros com algum tipo de pós-graduação. Além da academia, a Embrapa é também um forte incentivador. 
Apesar do sucesso, segundo levantamento feito pelo professor da Esalq USP, Mateus Mondin, $80 \%$ das startups encontram dificuldade para captar investimentos e $42 \%$ financiaram do próprio bolso. Com isso é constatada a necessidade de linhas de crédito e de uma educação empresarial para os jovens empreendedores. O professor afirma ainda que são necessárias novas linhas de crédito para esse mercado, além de visão de negócio - "muitos empreendedores que saem da academia pensam como cientistas, e não como empresários" (Estadão Conteúdo, 2017).

A resistência ao novo vem diminuindo e tende a diminuir ainda mais. Aquela imagem do "velho agricultor" tem sido desmistificada dia após dia. Hoje cerca de 67\% dos produtores usam o Facebook e $96 \%$ o WhatsApp, não só para lazer, mas também para negócios. Assim, devido à grande quantidade de startups nesse segmento e o crescente número de novas startups que surgem voltadas para o agronegócio, ainda que exista desconfiança, hoje existem soluções para todos os públicos, seja independente do porte ou do capital que o agricultor possui.

\section{METODOLOGIA DE PESQUISA}

Para maior detalhamento das agrotechs inseridas no mercado brasileiro, o presente trabalho buscou tangibilizar as características de algumas empresas por meio de um questionário aberto. Segundo Nogueira (2002), os questionários abertos têm como vantagem principal não restringir as respostas, possibilitando assim explorar a reposta de acordo com a experiência daquele que o responde.

Assim, para fins de pesquisa e mapeamento de algumas agrotechs em que o objetivo era que o entrevistado pudesse descrever sua vivência neste mercado, foi realizado um questionário via email com participantes da Inovativa 2016. A InovAtiva é um programa de aceleração em larga escala, para negócios inovadores no Brasil. O mesmo conta com capacitação especializada e conecta as startups participantes à investidores estratégicos.

As perguntas buscam entender qual o produto oferecido pela empresa, as fontes de investimento e aporte financeiro, bem como quais os principais motivadores e desafios encontrados pela empresa ao iniciar seu negócio. O questionário completo está descrito no ANEXO A deste trabalho. 


\section{AGROTECHS PESQUISADAS}

Serão analisadas as respostas de 3 agrotechs que participaram da Inovativa e se prontificaram a responder o questionário, bem como as semelhanças e diferenças entre elas. As empresas concordaram em apresentar os resultados de suas respostas por meio de nominação genérica e serão então nomeadas como Agrotech 1, Agrotech 2 e Agrotech 3. Todas as respostas referentes às empresas foram extraídas das pesquisas realizadas pelos respectivos contatos.

As três empresas pesquisadas foram incubadas para sua criação. Segundo o CENTEC, incubadoras são "ambientes planejados para o desenvolvimento das empresas, colocando à disposição das mesmas infraestrutura física, serviços de consultoria em gestão administrativa e operacional, facilitando a intermediação entre as empresas incubadas e os potenciais investidores, tais como instituições de ensino e pesquisa, governos e outros." As incubadoras são essenciais para startups que estão começando e auxiliam no início do negócio, reduzindo inclusive nas chances de fracasso da empresa, esse auxílio dá-se por meio de vários aspectos comerciais importantes, entre eles:

- Identificar o melhor modelo de negócios para o projeto;

- Criar um plano de negócios consistente;

- $\quad$ Criar um plano de marketing;

- Desenvolver a noção contábil da startup;

- Treinar o lado empresarial dos sócios; e

- Ajudar a encontrar algum investidor para o projeto.

Descrevendo sucintamente o caráter de pesquisa e atuação em cada uma das empresas, a Agrotech 1 desenvolveu um composto que alinha alta eficiência e baixo custo para o combate às pragas de fruticulturas. A Agrotech 2 utiliza tecnologias de sistemas baseados em inteligência artificial, capaz de identificar o índice de qualidade de produtos agrícolas. Por fim, a terceira startup em questão (Agrotech 3) tem como foco principal reaproveitamento e utilização da biotecnologia, transformando resíduos de animais em óleos e compostos orgânicos.

Abaixo, há a descrição dos aportes financeiros recebidos pelas empresas em questão, bem como o valor aproximado recebido. É importante destacar que as três 
empresas analisadas receberam aporte de alguma instituição ou fundação de amparo à pesquisa e à tecnologia. O presidente do Sebrae, Guilherme Afif [NoMinuto.com, 2017], destaca inclusive que "a inovação está em toda parte e deve ser incentivada, especialmente para garantir a competitividade dos pequenos negócios" justificando assim o incentivo ao desenvolvimento de startups e inovação a partir de novas tecnologias.

Tabela 1: Descrição dos aportes financeiros recebidos

\begin{tabular}{|r|c|c|}
\hline Empresa & Aporte (R\$) & Fontes \\
\hline Agrotech 1 & 50.000 & FAPESP \\
\hline Agrotech 2 & 100.000 & FAPESP e Prêmio de Reconhecimento \\
\hline Agrotech 3 & 1.000 .000 & FINEP, FUNCAP, SECITECE, CNPq, SENAI \\
\hline
\end{tabular}

Fonte: Autores (2018).

\subsection{Motivadores da criação da startup}

A pesquisa visou abordar ainda quais os motivadores levaram à criação da agrotech em questão. A Agrotech 1, destacou como motivador principal a ineficiência e alto custo do concorrente de combate às pragas na fruticultura e tem como principal objetivo reduzir os prejuízos causados pelas pragas no setor da fruticultura, que hoje têm um faturamento anual de 2 bilhões de reais em exportações. A Agrotech 2 teve como principais motivadores a possibilidade de autonomia com a criação de um negócio próprio, bem como o anseio de fazer a diferença e trazer benefícios para o país. Por fim, a Agrotech 3 transformou um problema ambiental em negócio, através do reaproveitamento de resíduos.

\subsection{Desafios encontrados}

Além dos motivadores que levaram os empreendedores a começarem o próprio negócio, foram levantados ainda os principais desafios por eles encontrados. A Agrotech 1 destacou como sua principal dificuldade o registro do produto na ANVISA, por se tratar de um produto para controle de pragas na fruticultura e estar diretamente relacionado ao ramo alimentício. A Agrotech 2, elencou como suas principais dificuldades o planejamento estratégico e o desafio de vendas e marketing. Já a Agrotech 3 teve como principais 
desafios a escassez de água para desenvolvimento dos produtos, necessitando assim de tecnologias alternativas para reuso da água e para dar continuidade ao projeto.

\subsection{Tecnologia e Inovação}

Como já definido anteriormente, startups são empresas de pequeno porte que contam com investimento inicial e geralmente focam em novas tecnologias. Assim, outro ponto mapeado entre as Agrotechs analisadas foi como as mesmas fazem uso de novas tecnologias e consequentemente, como são consideradas inovadoras.

Para a Agrotech 1, a tecnologia foi fundamental para seu desempenho, já que seu produto se baseia em uma fórmula para combater pragas na cultura de frutas. Sua inovação é justamente na composição do líquido, que apresenta alta durabilidade, baixo custo e eficiência duas vezes superior à de seu concorrente. Além disso, o fato de o composto não estar em contato direto com o alimento, faz com que o mesmo seja considerado "orgânico", gerando receita de até 30\% nas vendas das frutas.

Na Agrotech 2, a tecnologia e a inovação se deram por meio do desenvolvimento de softwares de inteligência artificial para aplicações que não existiam antes. Já a terceira agrotech analisada também contou com a utilização da tecnologia, embora a inovação da mesma baseou-se em adaptar conhecimentos e processos já existentes para a realidade do negócio, possibilitando o acesso ao mercado de forma imediata.

Por fim, as empresas analisadas têm em sua totalidade preocupação com o cunho ambiental e seus projetos visam reduzir e mitigar os impactos ambientais seja por meio de produtos químicos, mas não tóxicos, ou pelo reaproveitamento de resíduos que seriam despejados no meio ambiente.

\section{CONCLUSÃO}

O mercado do agronegócio cresce cada vez mais e hoje é responsável por metade das exportações brasileiras. Este crescimento é marcado pelo aumento na quantidade de startups nesse nicho, que duplicou nos últimos dois anos. A expansão neste mercado deuse pela necessidade de novas tecnologias e modernização e tem como objetivo diminuir custos e otimizar recursos nas mais variadas etapas do ciclo produtivo. 
Assim, analisando agrotechs específicas, foi possível perceber que algumas características são inerentes do modelo de startups e as voltadas ao agronegócio não são diferentes. Como exemplos podemos citar a captação de recursos por meio de investidores e aportes financeiros, bem como através de programas estatais ou privados de incentivo ao desenvolvimento e à tecnologia.

As agrotechs em questão seguem os mesmos princípios das demais startups: são inovadoras e estão associadas às novas tecnologias. É importante destacar ainda que dentre as analisadas, há um consenso quanto à necessidade de preservação ambiental para sucesso do negócio, assim, é importante que as tecnologias escolhidas levem em consideração este quesito para desenvolvimento das soluções que serão implementadas.

Com isso, podemos concluir que as empresas que responderam ao questionário têm as características de startups comuns e enfrentam desafios como falta de planejamento estratégico e ainda a necessidade de mudar o mindset da comunidade na qual a empresa está inserida.

O presente trabalho visou auxiliar no mapeamento e entendimento de como está o mercado do agronegócio no Brasil e inserido neste, como estão as agrotechs. Além disso, o objetivo era mapear através do questionário alguns negócios neste ramo para entender o que os mesmos têm em comum e quais as diferenças entre eles, seja pela localização geográfica, viés de pesquisa ou tecnologia necessária e disponível envolvida em cada caso. A principal dificuldade encontrada no processo de criação deste trabalho foi a pouca quantidade de agrotechs que se prontificaram a responder o questionário. Por este motivo, as startups que responderam o questionário foram analisadas detalhadamente e suas respostas foram tratadas de maneira quantitativa, comparando-as com as demais.

\section{AGRADECIMENTOS}

Os autores agradecem ao Fórum de Inovação e Competitividade Sustentável da UFABC (FICS/UFABC) pelo apoio nesta pesquisa.

\section{REFERÊNCIAS BIBLIOGRÁFICAS}


BARON, Robert A.; SHANE, Scott A. Empreendedorismo - Uma Visão Do Processo. Cengage Learning, 2007.

BATALHA, Marco Antonio; ARAGAKI, Sônia; MANTOVANI, Waldir. Variaçoes fenológicas das espécies do cerrado em Emas-Pirassununga, SP. Acta Botanica Brasilica, v. 11, n. 1, p. 6178, 1997.

BRASIL, Portal. Programa de incentivo a startups abre inscrições. Disponível em: <http://www.brasil.gov.br/economia-e-emprego/2017/01/programa-de-incentivo-astartups-abre-inscricoes>. Acesso em: 29 abr. 2018.

CAMARGO, Denise de; CUNHA, Sieglind Kind da; BULGACOV, Yára Lúcia Mazziotti. A Psicologia de Mcclelland e a Economia de Schumpeter no Campo do Empreendedorismo. Rde - Revista de Desenvolvimento Econômico, Salvador, n. 17, p.111-120, jan. 2008.

CLICO. Entenda como uma incubadora vai ajudar sua Startup a decolar. Disponível em: $<$ https://guiaempreendedor.com/entenda-como-uma-incubadora-vai-ajudar-sua-startupa-decolar/>. Acesso em: 12 abr. 2018.

Estadão Conteúdo; No campo, a revolução das startups publicado em 17 set 2017, Disponível em: < https://exame.abril.com.br/pme/no-campo-a-revolucao-das-startups/>. Acesso em: 14 Abril, 2020.

FIORIN, Márcia Meira Berti; MELLO, Cristiane Marques de; MACHADO, Hilka Vier. Empreendedorismo e Inovação: Análise dos Índices de Inovação dos Empreendimentos Brasileiros com Base nos Relatórios do GEM de 2006, 2007 e 2008. Rev. Adm. Ufsm, Santa Maria, v. 3, n. 3, p.411-423, set. 2010.

Incubadora do Instituto CENTEC - INTECE. Disponível em: <http://www.centec.org.br/index.php/programas-a-projetos/incubadora-intece/intece>. Acesso em: 05 abr. 2018.

LANDSTRÖM, Hans; BENNER, Mats. Entrepreneurship research: a history of scholarly migration. Historical foundations of entrepreneurship research, p. 15-45, 2010.

LANDSTRÖM, Hans; HARIRCHI, Gouya; ÅSTRÖM, Fredrik. Entrepreneurship: Exploring the knowledge base. Research Policy, v. 41, n. 7, p. 1154-1181, 2012.

LEMOS, Cristina. Inovação na era do conhecimento. Parcerias estratégicas, v. 5, n. 8, p. 157 180, 2009.

LIMA, Jairo Gustavo de; POZO, Osmar Vicente Chévez; FREITAS, Rodrigo Randow de; MAURI, Gabriela de Nadai. Startups no Agronegócio Brasileiro: uma revisão sobre as potencialidades do setor. 15 f. - Ufes, 2017.

MICHAELIS, Dicionário. Disponível em:< http://michaelis. uol. com. br>. Acesso em, v. 13, 2018.

MOREIRA, Daniela. O que é uma startup? Publicado em 3 fev 2016, Disponível em: <https://exame.abril.com.br/pme/o-que-e-uma-startup/\#>. Acesso em: 14 Abril. 2020.

MURPHY, Patrick J.; LIAO, Jianwen; WELSCH, Harold P. A conceptual history of entrepreneurial thought. Journal of management history, 2006.

Nei Grando Blog Finanças para Startups 31/07/2014, Disponível em: <https://neigrando.com/2014/07/>. Acesso em: 14 Abril, 2020. 
NOGUEIRA, Roberto. Elaboração e Análise de Questionários: uma revisão da literatura básica e a aplicação dos conceitos a um caso real. 28 f. - Ufrj, Rio de Janeiro, 2002.

PANTALEÃO, Luiz Henrique; ANTUNES JÚNIOR, José Antonio Valle; PELLEGRIN, Ivan de. A inovação e a curva da riqueza. 2007. 10 f. Tese (Doutorado) - Simpep, 2007.

Portal Brasil; publicado em 23 jan 2017; Disponível em: < https://nominuto.com/noticias/tecnologia/programa-de-incentivo-a-startups-abreinscricoes/151531/> Acesso em: 14 Abril, 2020.

SCHUMPETER, Joseph A. Teoria do desenvolvimento econômico. RJ: Fundo de Cultura, 1961.

SILVA, Álvaro José Argemiro da. Empreendedorismo e inovação. 2015.

VERGA, E.; SILVA, L. F. S. Empreendedorismo: evolução histórica, definições e abordagens. Revista de Empreendedorismo e Gestão de Pequenas Empresas, v. 3, n. 3, p. 3-30, 2014.

\section{ANEXO A - QUESTIONÁRIO}

Importante: Novamente, obrigada pela participação. Caso prefira não responder alguma questão, sem problemas! Deixe em branco e utilizaremos apenas as demais respostas para análise de dados.

1.Quais os principais dados cadastrais da empresa (nome, incubadora, site, data de início)?

2. Qual o quadro societário da mesma?

3. Descreva sucintamente o produto/serviço oferecido pela empresa.

4. A startup recebeu aporte financeiro? De quem? Que valor?

5. Quais os motivadores para iniciar o negócio?

6. Quais os desafios encontrados no início do negócio? E atualmente?

7. Já concluíram o MVP (Minimum Viable Product)?

8. Como o uso da tecnologia auxilia no seu negócio?

9. A empresa pode ser considerada inovadora? Por que?

10. A empresa adota práticas de preservação e/ou conservação ambiental durante seu processo de atuação? Se sim, quais?

\section{ANEXO B - LISTA DE SIGLAS}

ABStartups - Associação Brasileira de Startups

ANVISA - Agência Nacional de Vigilância Sanitária

CENTEC - Instituto Centro de Ensino Tecnológico 
CNPq - Conselho Nacional de Desenvolvimento Científico e Tecnológico

EMBRAPA - Empresa Brasileira de Pesquisa Agropecuária

FAPESP - Fundação de Amparo à Pesquisa do Estado de São Paulo

FINEP - Financiadora de Estudos e Projetos

FUNCAP - Fundação Cearense de Apoio ao Desenvolvimento Científico e Tecnológico

PIB - Produto Interno Bruto

SECITECE - Secretaria da Ciência, Tecnologia e Educação Superior

SENAI - Serviço Nacional de Aprendizagem Industrial

UFABC - Universidade Federal do ABC 